\title{
Some Perspectives Moving Forward
}

\subsection{Introduction}

The most severe part of a crisis is the most difficult phase for decision makers to face because the environment is dynamic and unstable, forcing crisis units to operate in degraded conditions. The fragilities that can appear within a crisis unit expose it to several types of disturbances. The rush of events, the massive arrival of information, sometimes incomplete or contradictory, and the need to report in a public way on the actions taken are just a few examples. These factors can thus destabilize the members of a crisis unit. Faced with emergency decision-making, they must nevertheless continue to carry out their missions and implement appropriate measures and means to protect the people, property and environment affected by the event.

In order to better understand the difficulties that reduce its effectiveness, it is necessary to understand the composition and functioning of a strategic crisis unit. A crisis unit goes beyond the status of a simple "group" described as an ephemeral organization. The crisis unit's strong organizational integration requires a high

Chapter written by Sophie SaUvagnargues, Dimitri LaPierre, Philippe Limousin, Noémie Fréalle, Florian Tena-Chollet, David Goutx, Pierre-Alain Ayral, Aurélia BONY-DANDRIEUX and Jérôme TIXIER. 
capacity to adapt to an unknown situation, while its members assume various roles and responsibilities that are finely structured and hierarchical. The members of a crisis unit are mobilized according to the skills and knowledge they possess to achieve their missions. While the need to carry out the tasks assigned to them is essential today, it is also necessary to note the importance attached to the various teamwork processes to achieve this. The analysis of different behavioral, cognitive and motivational processes allows us to stress the importance of "teamwork" in a team that pursues common objectives, whatever the function of each one may be. The influence of the group on decision-making, the existence of strongly involved sensitive issues, a temporal pressure, or even political problems associated with the representation of the situation as well as a whole set of cognitive biases degrade the entire process, from the perception of the situation to decision-making.

Today, it is therefore necessary that crisis managers are trained and that crisis management training sessions fully correspond to the needs identified. This requirement is justified by regulatory constraints, and it is also fundamental that decision makers gain experience and strengthen their levels of expertise. Among other things, training must allow for the reduction of dysfunctions identified at the collective and individual levels which occur in crisis units.

Retrospective analysis of these difficulties encountered by decision makers and their teams during strategic crisis management highlights the positive impact of the experience on the processes of coordination, shared mental representation, organization of intergroup behavior and decision-making. The need to set up training exercises is therefore based on the importance of reproducing specific complex and uncertain, urgent and unknown, catastrophic and destabilizing situations in the long term.

Research results (Tena-Chollet 2012; Lapierre 2016; Limousin 2017; Fréalle 2018) have highlighted the importance of the decision maker and their team's ability to perform crisis management strategies by integrating their feedback into scenarios reproducing the conditions 
and situations with which they have already been confronted. It is imperative for the decision maker and their team to be able to maintain an optimal level of involvement and mobilization of key crisis management skills during exercises simulating unforeseen or unknown events inherent in any major crisis.

To integrate these research results, a simulator was used as a support, which is a real semi-virtual training environment for strategic crisis management. This environment is based on a design methodology that uses a triple temporal-system-functional approach aimed at characterizing the essential components and interactions expected from a training platform.

Within this research platform, it is thus possible to develop and test different facilities, and to immerse trainees in crisis situations by isolating them in a room and reestablishing the a crisis unit.

Works on crisis management training have shown that the preparation, organization, animation and retrospective analysis of exercises are characterized by difficulties and problems related not only to the problem concerned but also to the inadequacy of the technical-pedagogical framework with respect to the profiles and needs of participants.

The review of knowledge in terms of organizational learning and teaching environment has also allowed the identification of perspectives and ways of improvement, in terms of both realistic simulation of a crisis scenario and optimization of the teaching processes involved and of the tools implemented.

\subsection{Understanding what is played out in a crisis unit}

\subsubsection{From the observation and debriefing point of view}

The consideration of human and organizational factors and the formalization of the evaluation during crisis management training allows us to propose a relevant observation of what plays out during a 
training and thus to produce an analysis by debriefing on the performances of learners during exercises.

Based on this situation, an EVADE (Evaluation and Debriefing Assistance) evaluation method has been developed, which simultaneously integrates the technical and non-technical expectations of a crisis unit and is applicable on a collective scale (Lapierre 2016). This innovative method proposes to carry out an evaluation in real time, with two main objectives: to make the training courses more immersive and dynamic (by adapting the scenario and requesting skills according to the choices chosen by learners) and to be an aid to debriefing.

In order to move forward, this evaluation methodology and debriefing assistance would require establishing the educational reference framework created (voluntarily generic and transposable) with different organizations. It would be interesting to propose an initial in-depth assessment of the skills of learners who need to participate in crisis management training. This pre-assessment could include a mapping of learners' skills before training in order to identify the benefits. It could take the form of individual questionnaires or interviews, specific to the crisis management organization and to the functions that members perform through their respective sub-units. This would allow evaluators to focus and select the instructional objectives of exercises. During a simulation, they could then verify the mobilization, acquisition, development and/or consolidation of the identified skills.

Moreover, integrating this type of methodology into a training plan would allow for a follow-up within the organization of several exercises to evaluate the progress margin of the members of the crisis unit throughout their learning process. The skill-based approach as well as the gradation aspect symbolized by the three difficulty levels (beginner, intermediate and expert) would be interesting in this case. 


\subsubsection{From the physiological and behavioral point of view}

The human organism is a set of systems regulated and interconnected in order to adapt to environmental stimuli. Thus, when performing a task, the nervous system stores relevant information, plans a response and then activates and regulates the functioning of the muscular system. As a result, the cardiovascular system, more intensely stressed, adjusts its components. In particular, it has been shown that during a cognitive task, the increase in cognitive load leads to the modulation of each of these systems. Indeed, an increase in heart rate and a decrease in its variability have been observed (Matthews et al. 2015). In brain imaging, an increase in signal amplitude at the prefrontal level (Ayaz et al. 2012) and frequency modulation at the centro-parietal and occipital levels have been observed (Käthner et al. 2014; Causse et al. 2015).

In the context of crisis management, it is essential to have tools that offer the possibility of optimizing operators' performance. Indeed, in this type of situation, the stressful context and the important stakes add many parameters that amplify the biological limits of the operator, as in the case of attentional blink (Dehais et al. 2014). Recent studies (Aghajani and Omurtag 2016) have suggested that the combination of several physiological data would allow better decoding of physiological signatures of cognitive load.

It would therefore be relevant to develop devices (biomedical, psychosensory, home automation, voice, indoor location, etc.) using a multi-domain approach to observe or characterize behavioral processes, cognitive and motivational measures of individuals subjected to decision-making in emergency situations and in confined environments, such as crisis units, and an analytical method for combining these measures to identify a physiological signature of increased workload in working memory. This approach, currently being developed as part of an interdisciplinary project (a collaboration between EUROMOV University of Montpellier and IMT Mines Alès-LGI2P-Institut des Sciences des Risques), is used in many fields such as behavioral neurosciences, neuropsychology, artificial learning, 
transfer learning, rehabilitation medicine, risk sciences and major crisis management. The use of crisis management training sessions is a testing ground in this particularly innovative field.

\subsection{Developing new methods to improve learner immersion}

\subsubsection{Getting closer to reality, or modifying it}

Knowledge of the simulated phenomenon during the exercise is a necessary precondition for the construction of the crisis management exercise. It is possible to use feedback from major past events in order to study the phenomenon via modeling. If this feedback brings positive realism to the simulation (it has happened!), it can lead to a bias during the exercise by calling upon the memory of "players". This is the case, for example, when working on cyclonic risk, where it is possible for some players to recognize the cyclone "played" very early in the simulation by observing the characteristics presented during the simulation. In this context, modeling can be an important means of generating an "unprecedented" event and its associated consequences (Ayral et al. 2018).

If modeling is used before the simulation, the gain could also be important if it were possible to use it during the simulation. Indeed, during the crisis management exercise, the elements related to the phenomenon in the scenario are generally "rigid", and consequences or disruptive events serve as adjustment variables for the facilitator. Aggravating or reducing the intensity of a phenomenon during the simulation and the associated consequences could therefore constitute an important advantage for the facilitator. For example, during a flood scenario, it would be a matter of increasing the amount of rainfall and of generating the consequences in terms of flow, floodplain area and water levels. This could also be the increase in the wind in the event of forest fire, the importance of a leak in case of a gas release, the height of the swell and so on.

The computation times of physical and numerical models required to perform these simulations make it impossible to use them in the crisis management exercise context. Several avenues of research can 
be evoked: (1) developing a modeling scenario before the crisis management exercise or (2) using metamodels based on statistical approaches (neural networks, for example), which will, by learning, simulate the functioning of the physical model with a significant gain in computation times. Generating several scenarios upstream of the simulation with a model and using a metamodel during the simulation are two levers that should be explored considerably in further research.

\subsubsection{Encouraging learner engagement}

Serious games are devices that can help improve the truth of the learner's position.

They associate a serious objective with a game (Szilas 2007), and are used in various fields such as defense, health and education (Bellino and Colombi 2012). Their educational scope is actually in their definition: they are playful. They enable potential learning to be made effective as learning, as a complement to the selection of educational objectives used in developing a learning situation. The game reinforces the commitment of the player in their experience, and the implementation of the mechanics of scripting used in serious games (interactive narration) is an interesting research track, because during the "classic" scripting of a crisis exercise, the designer must choose between the coherence of the story and the freedom of characters, and try to establish a multilinear scenario. Interactive narration makes it possible to implement methodologies to adapt to the learner's choice, while maintaining the guideline of the scenario.

The analogy between the "classic" crisis scenario and interactive narration allows us to envisage research avenues (Fréalle 2018), in order to produce a methodology that allows the scenario to evolve despite potentially unpredictable choices of learners, constrain the game world to limit the participants' options, offer the tools to the master of animation to orchestrate the scenario, allow the scenario to evolve during the exercise and give the facilitators the opportunity to share their given elements during the scenario. 
Learning becomes more effective in an openly playful setting, through a reinforced engagement via the game's mechanisms. However, it is also possible to reach a certain depth of engagement, a true awareness of responsibility, when play takes hold of a seemingly serious training.

Ludicity is the part of the game inherent in the simulation of crisis management, and by exploiting its intrinsic mechanisms, it is possible to enrich the simulation without distorting its nature as a pedagogical exercise. In particular, beyond the learning of skills by their use in a situation quite close to reality, it is possible to give the simulation an emotional consistency, bringing its content even closer to the complexity of the experience lived in a real-world crisis management environment. This is what we have referred to as a high-resolution simulation.

A classical approach tends to spontaneously consider that reality is factual and true and that a simulation should approach it as far as possible. However, along with Baudrillard (1981), we can question this relationship of simulation with reality. Indeed, for the vast majority of people summoned to a real crisis room (apart from professionals such as the military and firefighters), experiences of crisis management are often limited to the idea that these exercises show how to behave correctly in a crisis situation. The simulation then comes as an extra layer of preparation that provides a fictitious baseline experience to which the future crisis manager will conform when plunged into real crisis management. In other words, real crisis management is not simply reaching the truth of what the simulation tries to approach, but perhaps the final stage of the simulation becomes the reality, which Baudrillard refers to as the simulacrum.

In this game of mirrors between simulation, simulacrum and reality, what ultimately matters is the truth of the participant's position in the simulation, and the lucidity of the way they look at what the Ludicity of the simulation reveals of their behavior and their ability, ultimately, to assume the responsibility that falls to them. 


\subsubsection{Developing credible, pedagogical and interactive exercise scenarios}

Implementing training involves providing an effective learning situation. It is necessary to set a number of pedagogical objectives that learners can achieve, to choose among the possible types of training the one that is best suited, and, when implementing training, it is essential to put in place elements that promote learning so that the learner is motivated and committed to learning.

The implementation of a simulation requires the development of a scenario whose success criteria are credibility, pedagogical scope and interactivity. In its preparation, the implementation of these criteria should be ensured. This implies a certain number of pedagogical choices (selection of the hazard, the type of crisis unit, etc.) and design choices (self-powered or controlled scenario structure, writing of the timeline, etc.) that are made before the exercise is carried out.

Interactivity criteria are essential during the execution of the scenario, and at present, there are few methods to integrate it into the exercise. The encouraging contributions of system engineering to automating the construction of crisis scenarios thus make it possible to present all the concepts and elements of scenario development, taking into account their possible interactions (Limousin et al. 2016). The methods used to facilitate crisis exercises are also of interest and, more specifically, the improvement of interactions between facilitators and learners in order to adapt the scenario to their reactions during the exercise. Modeling the circulation of information between learners and facilitators, and within the facilitators, makes it possible to propose a set of participative devices (collaborative map, animation handrail, facilitator situation points, etc.) that will contribute to maintaining a high level of interactivity during the exercise (Fréalle et al. 2017).

\subsection{Implementing innovative complementary tools}

Within the simulation and research platform of the Institut des Sciences des Risques (IMT Mines Alès), a software tool called TwitterLike was developed to simulate the media pressure on social 
networks, with an operation based on the Twitter platform. Based on a Twitter API and developed with web technologies (PHP language), TwitterLike is hosted on an IMT Mines Alès server and is accessible from the outside, which allows remote use (Pot 2015).

TwitterLike works as follows. Facilitators can endorse the identity of any actor or person involved in the crisis scenario and can thus send messages of different types (text only, text with photo) and nature (certified information, rumor, inaccurate information, etc.). The opportunity to load pre-recorded messages can make it easier to send messages when they are part of the scenario itself. The participants in the exercise (the crisis unit) assume the role of the mobilized organization (a local community, for example) and can implement its crisis communication strategy by responding (or not) to the messages that pass through and being proactive by passing instructions or denying rumors if they so wish.

During a TwitterLike simulation, the tool can retrieve tweets on Twitter in real time (if the option is enabled) and inject them into the TwitterLike message thread. This possibility makes users aware of the need to sort and prioritize the information received.

However, any message exchanged during a TwitterLike simulation remains limited to the TwitterLike tool, and is therefore not published on Twitter. A database is used to store the tweets exchanged in order to offer the possibility of post-exercise analysis.

This tool therefore makes it possible to raise awareness of the use of social media for emergency management, and several perspectives can be mentioned.

First of all, the enrichment of TwitterLike with eponymous social network features would contribute to making the simulation more realistic and to proposing real crisis communication training.

Finally, a transposition toward other useful or used social networks in crisis situations is envisaged. The development of a FacebookLike tool could, for example, make it possible to raise awareness of crisis 
communication among other types of public social networks not covered by a Twitter-type network.

\subsection{Conclusion}

Crisis management training is increasingly deployed within state or private organizations in order to better prepare decision makers to face potential crises.

Research on the subject is developing in parallel with the growing power of needs. In the chapters of this book, advances relating to the various phases of creation and realization of an exercise have been presented. It is also important to set out some research perspectives for the coming years.

Two main axes can be summarized from this perspective:

1) To increase the flexibility and realism of the scenarios in order to open up to more interactive, innovative and playful exercises for learners. This must involve the creation of more interactive scenarios that integrate participants' skills and needs as closely as possible. The issue is the immersion of learners in scenarios, which must be increased so that learning improves.

2) To improve the individual's physiological knowledge, and also that of a group subjected to strong constraints to better observe, evaluate and restore "the gain in knowledge, skills and abilities" acquired during a crisis simulation exercise. This knowledge should then be translated into practical tools for trainers to improve the debriefing phase that is essential for learning.

If it is now possible to create and execute scenarios by integrating essential prerequisites, it remains, however, essential that this be integrated into a continuous improvement process. This is in order to make crisis management exercises ever more effective and thus make them real areas for experimentation in the field of decision support systems in crisis situations. 


\subsection{References}

Aghajani, H., and Omurtag, A. (2016). Assessment of mental workload by EEG+ fNIRS. Engineering in Medicine and Biology Society (EMBC), 2016 IEEE 38th Annual International Conference of the IEEE, August, pp. 3773-3776.

Ayaz, H., Shewokis, P.A., Bunce, S., Izzetoglu, K., Willems, B., and Onaral, B. (2012). Optical brain monitoring for operator training and mental workload assessment. Neuroimage, 59(1), 36-47.

Ayral, P.-A., Fréalle, N., Sauvagnargues, S., Téna-Chollet, F., Agon, P., Amourdom, P., Bonnardot, F., Bousquet, O., Germain, M.-C., Hibon, P., Ivoula, J., Lecacheux, S., Meister, J., Paris, F., Pesnel, E., Quetelard, H., and Recouvreur, R. (2018). Exercices de gestion de crise à l'échelle communale en contexte cyclonique - Application aux communes de Saint-Paul et Sainte-Suzanne, 14ème Rencontre annuelle Géorisque, Montpellier.

Baudrillard, J. (1981), Simulacres et simulations. Galilée, Paris.

Bellino, C. and Colombi, T. (2012). Jouer pour apprendre : vers une ergonomie "ludopédagogique". Colloques scientifiques SEGAMED. Nice.

Causse, M., Fabre, E., Giraudet, L., Gonzalez, M., and Peysakhovich, V. (2015). EEG/ERP as a measure of mental workload in a simple piloting task. Procedia Manufacturing, 3, 5230-5236.

Dehais, F., Causse, M., Vachon, F., Régis, N., Menant, E., and Tremblay, S. (2014). Failure to detect critical auditory alerts in the cockpit: evidence for inattentional deafness. Hum. Factors, 56(4), 631-644.

Fréalle, N., Tena-Chollet, F., and Sauvagnargues, S. (2017). The animation in the execution of crisis management exercises. In Proceedings of the 14th International Conference on Information Systems for Crisis Response and Management: Agility if Coming, Comes, T., Bénaben, F., Hanachi, C., Lauras, M., and Montarnal, A. (eds). ISCRAM, Albi..

Fréalle, N. (2018). Formation à la gestion de crise à l'échelle communale : méthode d'élaboration et de mise en oeuvre de scénarios de crise crédibles, pédagogiques et interactifs. $\mathrm{PhD}$ Thesis, University of St-Etienne. 
Käthner, I., Wriessnegger, S.C., Müller-Putz, G.R., Kübler, A., and Halder, S. (2014). Effects of mental workload and fatigue on the P300, alpha and theta band power during operation of an ERP (P300) brain-computer interface. Biol. Psychol., 102, 118-129.

Lapierre, D., (2016). Méthode EVADE : Une approche intégrée pour l'EValuation et l'Aide au DEbriefing. PhD Thesis, University of Nîmes.

Limousin P., Tixier J., Bony-Dandieux A., Chapurlat V., and Sauvagnargues S., (2016). A new method and tools to scenarios design for crisis management exercises. Chem. Eng. Trans., 53, 319-324.

Limousin P., (2017). Contribution à la scénarisation pédagogique d'exercices de crise, PhD Thesis, Saint-Etienne School of Mines, Saint-Etienne.

Matthews, G., Reinerman-Jones, L.E., Barber, D.J., and Abich IV, J. (2015). The psychometrics of mental workload: multiple measures are sensitive but divergent. Hum. Factors, 57(1), 125-143.

Pot, M. (2015). Développement d'un outil de simulation d'un réseau social pour la formation à la gestion de crise. IUT Montpellier-Sète.

Szilas, N. (2007). A Computational model of an intelligent narrator for interactive narratives. Appl. Artif. Intell., 21(8), 753-801. doi: $10.1080 / 08839510701526574$.

Tena-Chollet, F. (2012). Elaboration d'un environnement semi-virtuel de formation à la gestion stratégique de crise, basé sur la simulation multi-agents. PhD Thesis, Saint-Etienne School of Mines, Saint-Etienne. 
1 